\title{
The value of combined use of survivin mRNA and matrix metalloproteinase 2 and 9 for bladder cancer detection in voided urine
}

\author{
Sanaa Eissa ${ }^{\mathrm{a}, *}$, Soheir Badr ${ }^{\mathrm{b}}$, Shadia Abd Elhamid ${ }^{\mathrm{c}}$, Azza Salah Helmy ${ }^{\mathrm{c}}$, Mohamed Nour ${ }^{\mathrm{b}}$ and \\ Mohamed Esmat ${ }^{\mathrm{d}}$ \\ a Biochemistry Department, Faculty of Medicine, Ain Shams University, Cairo, Egypt \\ ${ }^{\mathrm{b}}$ Oncolgy Diagnostic Unit, Faculty of Medicine, Ain Shams University, Cairo, Egypt \\ ${ }^{\mathrm{c}}$ Biochemistry Department, Faculty of Science, Ain Shams University, Cairo, Egypt \\ ${ }^{\mathrm{d}}$ Urology Department, Faculty of Medicine, Ain Shams University, Cairo, Egypt
}

\begin{abstract}
Objective: In a trial to improve the diagnostic efficacy of conventional urine cytology we determine survivin RNA and matrix metalloproteinase 2 and 9 in urine of bladder cancer cases.

Method: Voided urine specimens were collected from patients with histologically confirmed bladder urothelial carcinoma (Group 1; $n=46$ ), urological patients without urothelial carcinoma (Group 2; $n=20$ ), and healthy volunteers (Group 3; $n=$ 20). Urine cytology, survivin RNA was estimated by qualitative nested RT-PCR and MMP-2, MMP-9 activity were detected by gelatin zymography. The expression of survivin RNA and matrix metalloproteinase 2 and 9 in bladder cancer was compared with benign and normal cases.

Results: Positivity rates of survivin RNA and MMPs zymography were significantly different among the 3 groups. Urine survivin detection by qualitative nested RT-PCR showed $76.1 \%$ sensitivity and $95 \%$ specificity. The overall sensitivity, specificity of urinary MMP zymography was $67.3 \%, 90 \%$ respectively. The combined use of urine cytology with urine survivin or MMPs zymography increased sensitivity of urine cytology from $50 \%$ to $84.7 \%$. The highest sensitivity (95.6\%) was obtained on combining the three markers.

Conclusion: Survivin RNA and MMPS zymography can be considered as promising noninvasive markers for bladder cancer early detection. Combined use of the three markers improved the sensitivity for detecting bladder cancer.
\end{abstract}

Keywords: Survivin, MMPs, RT-PCR

\section{Introduction}

Bladder carcinoma is one of the most common urologic malignancies occurring worldwide [1]. In Egypt it accounts for $30 \%$ of all cancers [2] and has been associated with many pathogenetic factors, most commonly bilharzial infestation [3]. Definitive proof of bladder cancers requires invasive cystoscopic examinations. However, this procedure is uncomfortable and laborintensive, particularly in follow-up [4]. Although uri-

*Corresponding author: Sanaa Eissa, Medical Biochemistry and Molecular Biology Department, Faculty of Medicine, Ain Shams University, Cairo, Egypt. E-mail: dr_sanaa_eissa@yahoo.com. nary cytology is widely used for screening for bladder cancer, it is sometimes difficult to judge cytologic specimens, particularly for low-grade cancers [5]. Therefore new, noninvasive methods for bladder cancer detection would open new possibilities in diagnosis and monitoring [6], as well as in screening of groups at risk such as bilharzial infested patients [7-9]. An ideal test to monitor bladder cancer should be objective, noninvasive, easy to administer and interpret and have high sensitivity and specificity.

Survivin, also called Baculoviral IAP repeatcontaining 5 (BIRC5), is a human gene that is part of the inhibitor of apoptosis protein (IAP) family. Survivin was found during embryonic and fetal develop- 
ment, was completely down-regulated and undetectable in normal adult tissue, and became prominently reexpressed in all of the most common human cancers, including cancers of the lung, colon, pancreas, prostate, and breast [10]. Acting at the interface between apoptosis and mitosis, Survivin was shown to be both a chromosomal passenger protein and to prevent programmed cell death by inhibiting the actions of the cell-death terminal effectors caspases-3 and caspases-7 [11].

The MMPs (matrix metalloproteinase) are a family of zinc-dependent endopeptidases that have been associated with the ability of tumor cells to degrade extracellular matrix components during tumor cell invasion [12]. They are secreted as latent proenzyme which requires activation through proteolytic cleavage of $\mathrm{N}$ terminal prodomain and are detected in urine samples of bladder cancer patients either active or inactive [13]. MMPs, in particular interstitial collagenase (MMP-1), stromelysin-1 (MMP-3), stromelysin-3 (MMP-11), the gelatinases (MMP-2 and MMP-9) are found in enhanced amounts in tumor tissues, where they regulate tumor growth and metastasis, promoting the invasion of malignant cells [14] and obviously found to be associated with bad survival $[15,16]$. The aim of this study was to evaluate the expression of Survivin mRNA and Matrix Metalloproteinases activity in urine of malignant and benign bladder patients compared to normal control group and examined the usefulness of these markers for detection of bladder cancer.

\section{Materials and methods}

The study Population included 66 Egyptian patients admitted to the urological department Ain Shams Faculty of medicine. A blood sample and single voided urine sample were obtained from all patients after obtaining informed consent. A cytological test for urine sediment was done before cystoscopy. All patients underwent cystoscopy and histopathology as the reference standard to detect bladder carcinoma. Accordingly the 66 studied patients were classified into 46 with bladder cancer with a median age 61.5 years (range 26 to 83 ) and 20 with benign urological lesion with a median age 53 years (range 25 to 70 ). In bladder cancer, a total of 29 were transitional cell carcinoma and 17 were squamous cell carcinoma. Tumor were staged according to TNM classification of UICC criteria [17] and graded according to WHO criteria [18]. The study also included a group of 20 healthy volunteers with a median age 39 years (range 25 to 60) who were recruited from the laboratory staff.

\subsection{Sample preparation}

Venous blood (5 ml) and voided urine (30 to $60 \mathrm{ml}$ ) samples were obtained from all individuals before treatment or surgery. Each urine samples were collected into approved urine collection cups which were sealed immediately and placed on ice, then centrifuged for 15 to 20 minutes at 2,500 to $4,000 \mathrm{x}$ gravity and separated into supernatant and pellet. Pellets were washed twice with phosphate buffered saline, $\mathrm{pH}$ 7.0. A portion of the pellets was used for cytological and microscopic examination by a cytologist. The other portion was treated with $500 \mu \mathrm{l}$ protease inhibitor cocktail composed of $0.5 \mathrm{gm} / 100 \mathrm{ml}$ ethylene diamine tetra acetic acid-disodium dehydrate, $0.4 \mathrm{gm} / 100 \mathrm{ml}$ phosphomethylsulfonyl fluoride, $1,000 \mu \mathrm{l} / 100 \mathrm{ml}$ benzamidine and $100 \mu \mathrm{l} / 100 \mathrm{ml}$ aprotinin [19] and stored at $-80 \mathrm{C}$ for further processing to extract RNA for survivin detection.

\subsection{Detection of serum schistosomiasis antibodies}

Serum was used to detect schistosomiasis antibodies by the indirect hemagglutination test using the Cellognost ${ }^{\circledR}$ Schistosomiasis H kit [20].

\subsection{RNA extraction}

RNA was extracted using purescript RNA Isolation kit (Genera systems, Inc., Minneapolis, USA) [21]. Up to $1 \times 10^{7}$ cells were disrupted and homogenized with the lysis buffer (citric acid, EDTA and sodium dodecylsulfate 'SDS'). One volume of $70 \%$ ethanol was added to the lysate and up to $700 \mu \mathrm{l}$ of sample were applied to the RNeasy Mini spin column. high quality RNA was eluted in ribonuclease- free water.

\subsection{RT nested PCR for survivin $m R N A$}

Total RNA ( $2 \mu \mathrm{g})$ was subjected to first strand cDNA synthesis using Moloney murine leukemia virus RT and hexamer primer [pd (N)6] for 5 minutes at $35 \mathrm{C}$ and for 60 minutes at $43 \mathrm{C}$. The RT-PCR reaction was performed using Ready-to-Go ${ }^{\text {TM }}$ RT-PCR Beads After heating at $72 \mathrm{C}$ for 15 minutes a first amplification reaction was done with survivin primers (sense 5'-CTG CCT GGC AGC CCT TTC TCA A -3' and antisense 5'-AAT AAA CCC TGG AAG TGG TGC A-3') with initial melting at 94C for 5 minutes, 35 cycles of denaturation at $94 \mathrm{C}$ for 1 minute, annealing at $55 \mathrm{C}$ for 1 minute and extension at $72 \mathrm{C}$ for 2 minutes, 


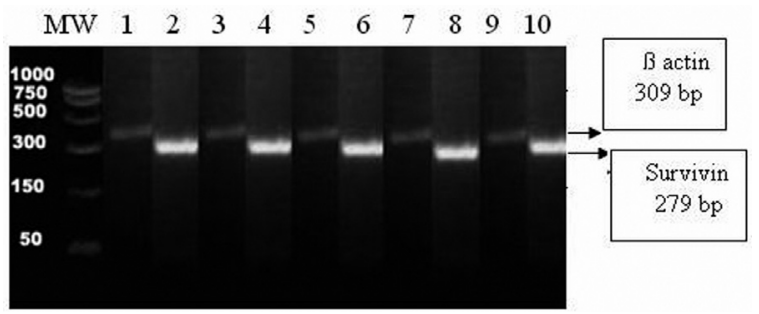

Fig. 1. RT nested PCR of urinary survivin at 279 bp and RT PCR of $\beta$-actin at $309 \mathrm{bp}$. Lane 1 , molecular weight ladder standard at 1,000 to $50 \mathrm{bp}$. Lanes 2 to 11 , bands positive for survivin and $\beta$-actin in bladder cancer samples.

Table 1

Survivin RNA and MMPs zymography, and urine cytology in study groups

\begin{tabular}{lccc}
\hline Groups & $\begin{array}{c}\text { No Pos }(\%) \\
\text { Survivin }\end{array}$ & $\begin{array}{c}\text { No Pos }(\%) \\
\text { MMPs }\end{array}$ & $\begin{array}{c}\text { No Pos }(\%) \\
\text { Cytology }\end{array}$ \\
\hline Malignant $(n=46)$ & $35(76.1)$ & $31(67.3)$ & $23(50)$ \\
Benign $(n=20)$ & $2(10)$ & $4(20)$ & 0 \\
Normal $(n=20)$ & 0 & 0 & 0 \\
Chi-square* $^{*}$ & 44.5 & 30.8 & 27.3 \\
\hline
\end{tabular}

${ }^{*} p<0.001$.

followed by incubation at $72 \mathrm{C}$ for 5 minutes. A $463 \mathrm{bp}$ fragment of survivin cDNA was subjected to a second round of amplification with nested survivin primers (sense 5'-CCGCATCTCTACATTCAAGAAC-3' and antisense (5'-CTTGGCTCTTTCTCTGTCC-3') with initial melting at $95 \mathrm{C}$ for 5 minutes, 30 cycles at $94 \mathrm{C}$ for 30 seconds, $60 \mathrm{C}$ for 30 seconds and $72 \mathrm{C}$ for 1 minute, and final extension at $72 \mathrm{C}$ for 5 minutes. The $279 \mathrm{bp}$ product for survivin was separated on $2 \%$ agarose and visualized by ethidium bromide staining [22]. $\beta$ actin was processed for use as a housekeeping gene. It's primer pair was sense 5' -AGCGGCAAATCGTGCG TG-3' and antisense 5' -CAGGGTACATGGTGCC 3' (Fig. 1).

\subsection{MMP zymography}

MMP zymography was performed according to the method of Heussen and Dowdle [23] and modified by Bianco et al. [24] $8 \%$ sodium dodecyl sulfate (SDS) mixed with gelatin ( $1 \mathrm{ml}$ of $1 \mathrm{~g} \%$ ) was used to separate $20 \mu \mathrm{g}$ sample protein of urine supernatant by miniprotean II (Bio-Rad Labs, USA) electrophoresis according to the method of Sambrook et al. [25]. The gel was removed when the tracking dye front had reached the bottom of the resolving gel and then washed twice (30 min each) under constant mechanical stirring in $200 \mathrm{ml}$ of $2.5 \%$ Triton X-100 at room temperature. The gel slabs were then immersed in detection buffer
Table 2

Survivin RNA and MMPs zymography, and urine cytology vs. bladder cancer group clinicopathological factors

\begin{tabular}{|c|c|c|c|}
\hline $\begin{array}{l}\text { Clinicopathological } \\
\text { Factor }\end{array}$ & $\begin{array}{c}\text { Survivin } \\
\text { No } \operatorname{Pos}(\%)\end{array}$ & $\begin{array}{c}\text { MMPs } \\
\text { No Pos }(\%)\end{array}$ & $\begin{array}{c}\text { Cytology } \\
\text { No Pos }(\%)\end{array}$ \\
\hline \multicolumn{4}{|l|}{ Gender } \\
\hline Male (35) & $27(77.1 \%)$ & $24(68.6 \%)$ & $16(45.7 \%)$ \\
\hline Female (11) & $8(72.7 \%)$ & $7(63.6 \%)$ & $7(63.3 \%)$ \\
\hline \multicolumn{4}{|l|}{ Smoking } \\
\hline- ve $(22)$ & $17(77.3 \%)$ & $15(68.2 \%)$ & $13(59.1 \%)$ \\
\hline+ ve $(24)$ & $18(75 \%)$ & $16(66.7 \%)$ & $10(41.7 \%)$ \\
\hline \multicolumn{4}{|l|}{ Bilharziasis } \\
\hline - ve (11) & $8(72.7 \%)$ & $8(72.7 \%)$ & $5(45.5 \%)$ \\
\hline+ ve $(35)$ & $27(77.1 \%)$ & $23(65.7 \%)$ & $18(51.4 \%)$ \\
\hline \multicolumn{4}{|l|}{ Pathology } \\
\hline TCC (29) & $21(72.4 \%)$ & $19(65.5 \%)$ & $15(51.7 \%)$ \\
\hline SCC (17) & $14(82.4 \%)$ & $12(70.6 \%)$ & $8(47.1 \%)$ \\
\hline \multicolumn{4}{|l|}{ Grade } \\
\hline Low grade $(\mathrm{I}+\mathrm{II})(36)$ & $28(77.7 \%)$ & $22(61.1 \%)$ & $18(50 \%)$ \\
\hline High grade (III) (10) & $7(70 \%)$ & $9(90 \%)$ & $5(50 \%)$ \\
\hline \multicolumn{4}{|l|}{ Stage } \\
\hline Early stage $(0+1)(15)$ & $13(86.7 \%)$ & $9(60 \%)$ & $7(46.7 \%)$ \\
\hline Late stage $(2+3)(31)$ & $22(70.9 \%)$ & $22(70.9 \%)$ & $16(66.7 \%)$ \\
\hline \multicolumn{4}{|l|}{ Cytology } \\
\hline - ve $(23)$ & $16(69.6 \%)$ & $16(69.6 \%)$ & - \\
\hline+ ve $(23)$ & $19(82.6 \%)$ & $15(65.3 \%)$ & - \\
\hline
\end{tabular}

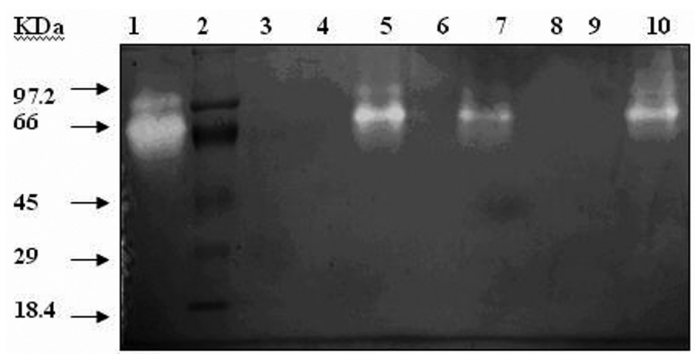

Fig. 2. Gelatin zymography for the enzymatic activity of MMP-2 and MMP-9. prestained molecular weight marker (14.7-97.2) at lane (2), Urine supernatant of bladder carcinoma. Lane1: - ve bilharziasis, SCC, grade 2, stage 1. lanes 3, 5: + ve bilharziasis, SCC, grade 2, stage 1. Lane 4: + ve bilharziasis, SCC, grade 2, stage 2 and Lane 6: + ve bilharziasis, SCC, grade2, stage 3), Urine supernatant of benign bladder $(7,8,9,10)$. Clear zones indicate gelatinolytic activity with molecular weights 92 KDa correspond to Pro-MMP-9, 72 KDa correspond to Pro-MMP-2 and 62KDa correspond to active isoforms of MMP-2.

and incubated at $37 \mathrm{C}$ for $24 \mathrm{~h}$. detection buffer was added $(50 \mathrm{mmol} / \mathrm{l}$ Tris- $\mathrm{HCl}(\mathrm{pH} 7.6), 0.2 \mathrm{~mol} / \mathrm{l} \mathrm{Na}-$ $\mathrm{Cl}$, and $5 \mathrm{mmol} / \mathrm{l} \mathrm{CaCl} 2$ ). The gels were then fixed and stained by immersion for $1 \mathrm{~h}$ in Coomassie Blue R250. Molecular weight protein maker appeared as easily visible staining bands against the lighter blue color of the stained gelatin background. Gelatinase activity was detected as clear zones of lyses (negative staining) 
Table 3

Combined sensitivity and specificity for survivin RNA and MMPs zymography, and urine cytology in detection of bladder cancer

\begin{tabular}{lrrrrr}
\hline Paramete & Sensitivity & Specificity & NPV & PPV & Accuracy \\
\hline Cytology & $50 \%$ & $100 \%$ & 63.45 & $100 \%$ & $73.2 \%$ \\
Survivin & $76.1 \%$ & $95 \%$ & $77.5 \%$ & $94.5 \%$ & $84.8 \%$ \\
MMP-Zymography & $67.3 \%$ & $90 \%$ & $70.5 \%$ & $88.5 \%$ & $77.9 \%$ \\
Cytology + Survivin & $84.7 \%$ & $95 \%$ & $84.4 \%$ & $95.1 \%$ & $77 \%$ \\
Cytology + MMP - Zymography & $84.7 \%$ & $90 \%$ & $83.7 \%$ & $90.6 \%$ & $87.2 \%$ \\
Survivin + MMP - Zymography & $91.3 \%$ & $85 \%$ & $89.4 \%$ & $87.5 \%$ & $88.3 \%$ \\
Cytology + Survivin + MMP - Zymography & $95.6 \%$ & $85 \%$ & $94.4 \%$ & $88 \%$ & $90.6 \%$ \\
\hline
\end{tabular}

against the blue background. The gels were scanned to make a permanent record of the results (Fig. 2).

\subsection{Statistical analysis}

The nonparametric Mann-Whitney sum rank U test and Kruskal-Wallis (x2) test were used for the comparison of the variables between groups. Positivity rates of studied parameters were compared among malignant, benign and control groups using chi square test. The level of significance was determined to be less than 0.05. All analysis was performed with the use of the Statistical Package for the Social Sciences (SPSS Inc, Chicago, IL, USA).

\section{Results}

Qualitative RT-PCR and MMPs zymography in 46 samples revealed positivity in $76.1 \%$ and $67.4 \%$, respectively, of the malignant group and in $10 \%$ and $20 \%$ of the benign group and not detected in normal individuals $(p<0.001$, Table 1$)$.

On correlating studied urinary markers with clinicopathological factors of bladder cancer group, no significant relation was found (Table 2).

Sensitivity and specificity for each urinary marker as well as their combination were tested for detection of bladder cancer. Both sensitivity and specificity of urinary survivin was the highest, whereas urine cytology revealed the lowest sensitivity. Combining survivin and MMPs increased sensitivity and specificity. Sensitivity of urine cytology improved when combined with survivin RNA or MMPs zymography while the best sensitivity for urine cytology was achieved when the 3 markers were combined (Table 3).

\section{Discussion}

Soluble molecular markers secreted in urine could serve as urinary markers for bladder cancer detection, depending on their efficiency to provide early detection capabilities and insight into appropriate treatment response and tumor recurrence [26]. Using nested RTPCR survivin mRNA expression in urine was determined by comparing the expression of the target gene survivin with that of the housekeeping gene $\beta$-actin, which is thought to be suitable to normalize expression. Our results revealed a marked increase in the positivity rate of urine survivin in the malignant vs. the benign group (76.1\% vs. $10 \%$ ) while no normal urine samples showed positive survivin RNA $(p<0.001)$. Moussa et al. [27] detected higher urine survivin RNA sensitivity (94\%) and specificity (95\%). Also, Smith et al. [22] reported absolute sensitivity at $95 \%$ specificity. In a recent study by $\mathrm{Ku}$ et al. [28], Bivariate random effect meta-analyses were used to calculate the summary estimated of sensitivity and specificity of urine surviving in 14 studies on 2051 subjects. The pooled sensitivity and specificity for urine survivin tests were $77.2 \%$ and $91.8 \%$ respectively which is nearly similar to our results. Discrepancies in urinary survivin mRNA sensitivity and specificity results may be attributable to the use of different types of samples, in which the number of living cells varies, proper transport and storage. In our laboratory we ensured the highest RNA quality by rapid sample washing, processing, preserving urine sediment in a protease inhibitor cocktail adapted at our laboratory and using a housekeeping gene to exclude samples with degraded RNA.

MMPs are important mediators of cancer progression and invasion [29]. Urinary MMPs-Zymograhpy is one of the few urinary markers approved by the food and drug administration for monitoring and detection of bladder cancer. MMPs levels in cancer patients could in turn reflect enhanced presence of these markers in the circulation, but in the case of bladder cancer they might also directly originate from the tumor and therefore could be particularly indicative for superficial bladder tumors [26].

Our results revealed marked increase of MMP-2 and MMP-9 levels in malignant group compared with benign and control groups. In one of the few studies mea- 
suring MMP-9 and MMP-2 in urine, Sier et al. [30] revealed increased level of both markers in the malignant group compared with a control group that did not include patients with benign urologic disease. This marked increase in MMPs in the malignant group is expected because MMP-2 is synthesized by tumor cells or quite commonly by host response to tumor as fibroblasts, macrophages, and vascular endothelial cells. However, MMP-9 is strongly expressed in intravascular and tissue-infiltrating leucocytes [31] and their implication in the pathogenesis of bladder cancer has been documented [30].

When a urine molecular marker is used for bladder cancer diagnostic assessment, it should have high sensitivity and PPV [27]. Accordingly urinary survivin mRNA and MMPs are significantly superior to urine cytology.

Urinary survivin levels were detected in the majority of bladder cancer cases misdiagnosed by MMPs zymography and cytology (false negative). This performance was achieved at the expanse of yielding a false positive rate of 5\%. Given the aggressive biological behavior of bladder cancer this minimal number of false positive results seems acceptable. In conclusion, combined use of survivin mRNA by nested RT-PCR and MMPs- zymography improve the sensitivity and specificity of urine cytology for diagnosis of bladder cancer.

\section{Acknowledgment}

This work was supported by the Egyptian Academy of Research and Technology, the Technical development and Scientific Sector. The Science and Technology Center, Project 21/2.

\section{References}

[1] A. Jemal, T. Murray, E. Ward, A. Samuels, R.C. Tiwari, A. Ghafoor, E.J. Feuer and M.J. Thun, Cancer Statistics. CA Cancer J Clin 55 (2005), 10-30.

[2] N.G. El-Mawla, M.N. El-Bolkainy and H.M. Khaled, Bladder cancer in Africa: update. Semin Oncol 8 (2001), 174-178.

[3] M. Gui, M.A. Idris, Y.E. Shi, A. Mühling and A. Ruppel, Reactivity of Schistosoma japonicum and S. mansoni antigen preparations in indirect haemagglutination (IHA) with sera of patients with homologous and heterogonous schistosomiasis. Ann Trop Med Parasitol 85 (1991), 599-604.

[4] M. Babjuk and J. Dvoracek, Diagnosis and therapy of superficial tumors of the urinary bladder. Cas Lek Cesk 141 (2002), 723-728.
[5] J.H. Hughes, S.S. Raab and M.B. Cohen, The cytologic diagnosis of low- grade transitional cell carcinoma. Am J Clin Pathol 114 (2000), 59-67.

[6] S. Eissa, S. Kassim and O. El-Ahmady, Detection of bladder tumors: role of cytology, morphology-based assays, biochemical and molecular markers. Curr Opin Obstet Gynecol 15 (2003), 395-403.

[7] S. Eissa, M. Swellam, A. Amin, M.E. Balbaa, G.A. Yacout and T.M. El-Zayat, The clinical relevance of urine-based markers for diagnosis of bladder cancer. Med Oncol 28 (2011), 513518.

[8] S. Eissa, M. Swellam, R.A. Labib, T. El-Zayat and O. El Ahmady, A panel of angiogenic factors for early bladder cancer detection: enzyme immunoassay and Western blot. J Urol 181 (2009), 1353-1360.

[9] S. Eissa, S.F. Zohny, M. Swellam, M.H. Mahmoud, T.M. ElZayat and A.M. Salem, Comparison of CD44 and cytokeratin 20 mRNA in voided urine samples as diagnostic tools for bladder cancer. Clin Biochem 41 (2008), 1335-1341.

[10] K. Tanaka, I. Shinji and G. Goki, Expression of survivin and its relationshipe to loss of apoptosis in breast carcinomas. Clinical Cancer Resersh (2000), 127-134,

[11] A. Krieg, C. Mahotka, T. Krieg, H. Grabsch, W. Müller, S. Takeno, C.V. Suschek, M. Heydthausen, H.E. Gabbert and C.D. Gerharz, Expression of different surviving variants in gastric carcinomas: First clues to a role of survivig-2B in tumors progression. British Journal of Cancer 86 (2002), 737743.

[12] F.J. Bianco, Jr., D.C. Gervasi, R. Tiguert, D.J. Grignon, J.E. Pontes, J.D. Crissman, R. Fridman and D.P. Wood, Jr., Matrix metalloproteinases- 9 expression in bladder washes from bladder cancer patients predicts pathological stage and grade. Clin Cancer Res 4 (1998), 3011-3016.

[13] A.F. Chambers and L.M. Matrisian, Changing views of the role of matrix metalloproteinases in metastasis. J Natl Cancer Inst 89 (1998), 1260-1270.

[14] T. Lizasa, K. Yasufuku, M. Baba and M. Shiba, Elevated levels of circulating plasma matrix metalloproteinas 9 in non-small cell lung cancer patients. Clin Cancer Res 5 (1999), 149-153.

[15] M. Seiki, Membrane-type1 matrix metalloproteinase: a key enzyme for tumor invasion. Cancer Lett 194 (2003), 1-11.

[16] N.E. Sounni and A. Noel, Membrane type-matrix metalloproteinases and tumor progression. Biochimie 87(2005), 329342.

[17] L.H. Sobin and C. Wittkind, UICC TNM Classification of Malignant Tumors, 5th ed. New York: Wiley Liss, 1997; p. 187.

[18] Histological Typing of urinary bladder Tumors. Geneva, Switzerland: World Health Organization; 1973.

[19] S. Eissa, M. Swellam, H. el-Mosallamy, M.S. Mourad, N. Hamdy, K. Kamel, A.S. Zaglol, M.M. Khafagy and O. elAhmady, Diagnostic value of urinary molecular markers in bladder cancer. Anticancer Res 23 (2003), 4347-4355.

[20] M. El-Sebaie, M.S. Zaghloul, G. Howard and A. Mokhtar, Evaluation of purified antigens in haemagglutination test (IHA) for determination of cross reaction in diagnosis of fascioliasis and schistosomiasis. Journal of the Egyptian society of Parasitology 26 (1996), 677-685.

[21] F.M. Ausubel, R. Brent, R.F. Kingston et al., Short protocols in molecular biology, a copendiun of methods from current protocols in molecular biology. 14th ed., New York, John Wiley, 1999, 1,8. 57-58. 
[22] S.D. Smith, M.A. Wheeler, J. Plescia, J.W. Colberg, R.M. Weiss and D.C. Altieri, Urine detection of survivin and diagnosis of bladder cancer. JAMA 285 (2001), 324-328.

[23] C. Heussen and E.B. Dowdle, Electrophoretic analysis of plasminogen activators in polyacrylamide gels containing sodium dodecyl sulfate and copolymerize substrates. Anal Biochem, 102 (1980), 196-202.

[24] F.J. Bianco, Jr., D.C. Gervasi, R. Tiguert, D.J. Grignon, J.E. Pontes, J.D. Crissman, R. Fridman and D.P. Wood, Jr., Matrix metalloproteinases 9 expression in bladder washes from bladder cancer patients predict pathological stage and grade. Clin Cancer Res, 4 (1997), 3011-4016.

[25] J. Sambrook, E.F. Fritsch and T. Maniatis, Molecular cloning. 3rd ed., Cold Spring Harbor Laboratory, 16 (1989), 42-51.

[26] S. Curran and G.I. Murray, Matrix metalloproteinases. Molecular aspects of their roles in tumor invasion and metastasis. Eur J Cancer, 36 (2000), 1621-1630.

[27] O. Moussa, H. Abol-Enein, N.K. Bissada, T. Keane M.A. Ghoneim and D.K. Watson, Evaluation of survivin reverse transcriptase-polymerase chain reaction for noninvasive detection of bladder cancer. J Urol, 175 (2006), 2312-2316.

[28] J.H. Ku, G. Godoy, G.E. Amiel and S.P. Lerner, Urine survivin as a diagnostic biomarker for bladder cancer: a systematic review. BJU Int, 2012. [Epub ahead of print].

[29] F. Monier, A. Surla, M. Guillot and F. Morel, Gelatinase isoforms in urine from bladder cancer patients. Clin Chim Acta, 299 (2000), 11-23.

[30] C.F. Sier, G. Casetta, J.H. Verheijen, A. Tizzani, V. Agape, J. Kos, F. Blasi and R. Hanemaaije, Enhanced urinary gelatinase activities (matrix metalloproteinases 2 and 9) are associated with early-stage bladder carcinoma: a comparison with clinically used tumor markers. Clin Cancer Res 6 (2000), 23332340 .

[31] E. Ozdemir, Y. Kakehi, H. Okuno and O. Yoshida, Role of matrix metalloproteinase-9 in the basement membrane destruction of superficial urothelial carcinomas. J Urol, 161 (1999), $1359-1363$ 


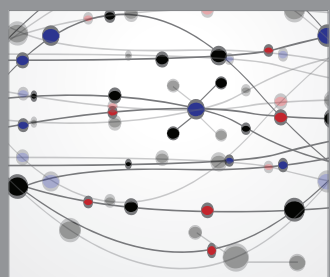

The Scientific World Journal
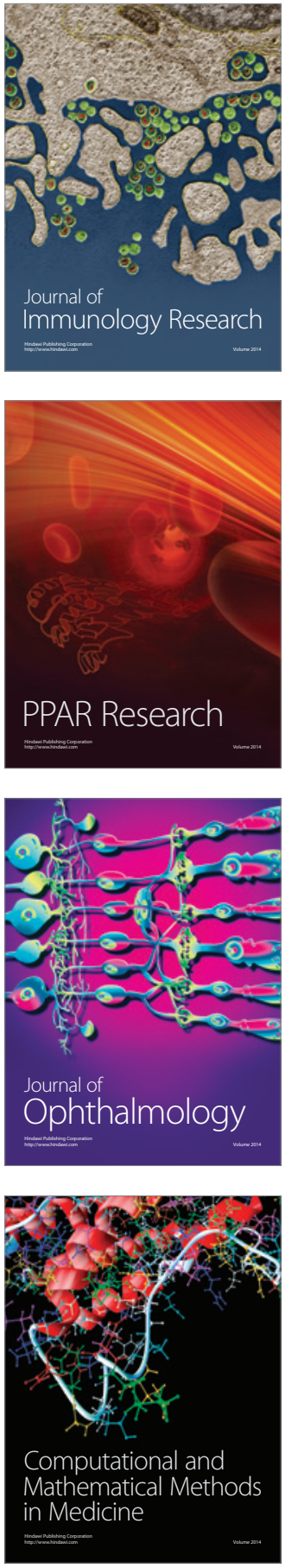

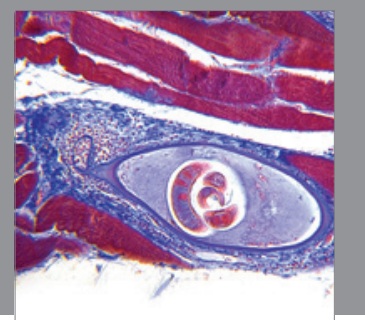

Gastroenterology

Research and Practice
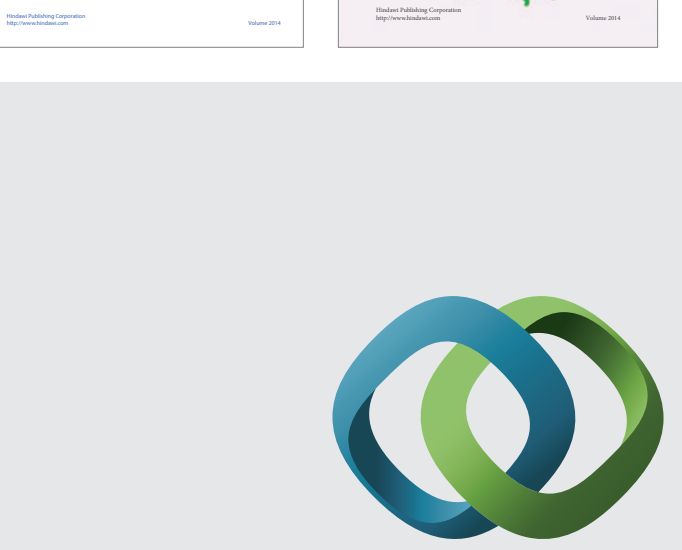

\section{Hindawi}

Submit your manuscripts at

http://www.hindawi.com
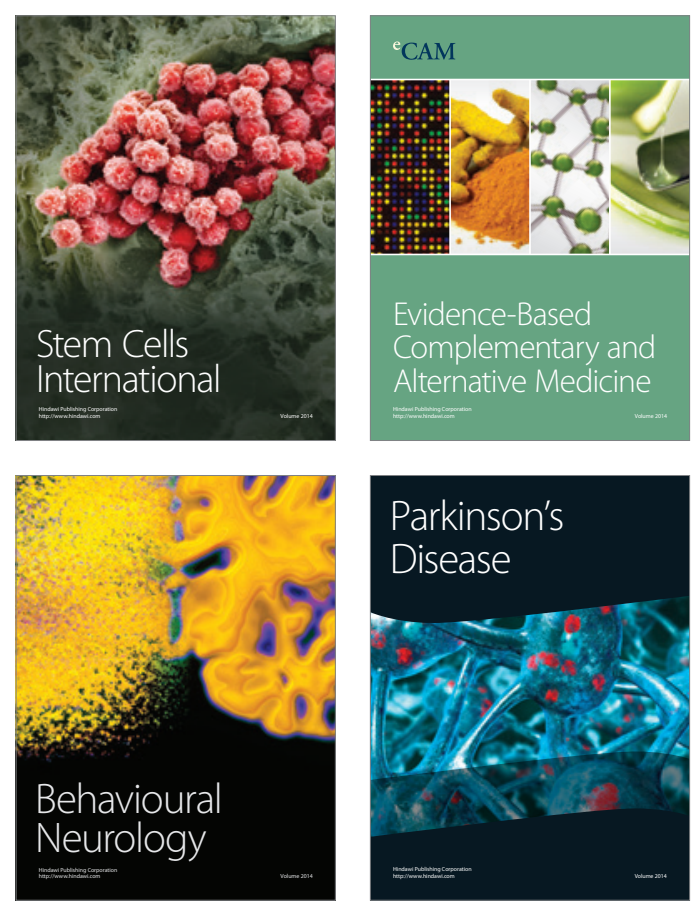

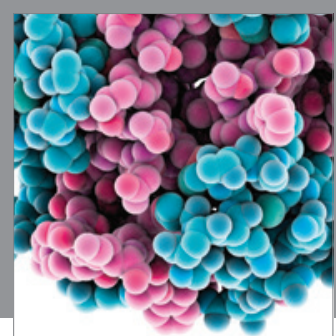

Journal of
Diabetes Research

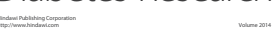

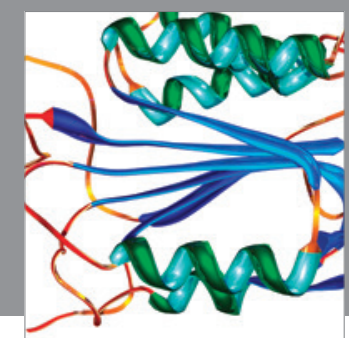

Disease Markers
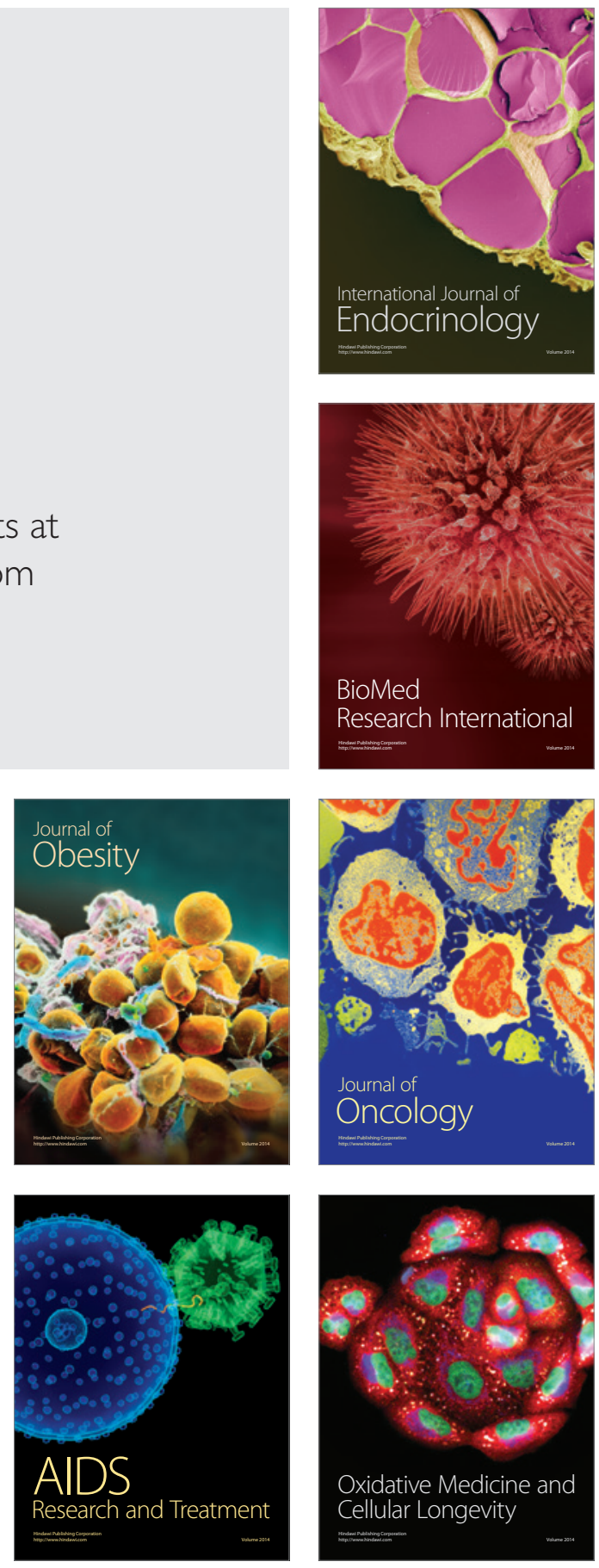